ARTICLE

\title{
Fast ion transport for synthesis and stabilization of $\beta-\mathrm{Zn}_{4} \mathrm{Sb}_{3}$
}

Dongwang Yang ${ }^{1}$, Xianli Suํ, Jian He (1) ${ }^{2 凶}$, Yonggao Yan ${ }^{1}$, Jun $\mathrm{Li}^{1}$, Hui Bai ${ }^{1,3}$, Tingting Luo ${ }^{1,3}$, Yamei Liu (D) ${ }^{2}$, Hao Luo ${ }^{1,3}$, Yimeng $Y u^{1,3}$, Jinsong Wu (1) ${ }^{1,3 凶}$, Qingjie Zhang ${ }^{1}$, Ctirad Uher ${ }^{4} \&$ Xinfeng Tang $\mathbb{( D}^{1 凶}$

Mobile ion-enabled phenomena make $\beta-\mathrm{Zn}_{4} \mathrm{Sb}_{3}$ a promising material in terms of the re-entry phase instability behavior, mixed electronic ionic conduction, and thermoelectric performance. Here, we utilize the fast $\mathrm{Zn}^{2+}$ migration under a sawtooth waveform electric field and a dynamical growth of 3-dimensional ionic conduction network to achieve ultra-fast synthesis of $\beta-\mathrm{Zn}_{4} \mathrm{Sb}_{3}$. Moreover, the interplay between the mobile ions, electric field, and temperature field gives rise to exquisite core-shell crystalline-amorphous microstructures that selfadaptively stabilize $\beta-\mathrm{Zn}_{4} \mathrm{Sb}_{3}$. Doping $\mathrm{Cd}$ or $\mathrm{Ge}$ on the $\mathrm{Zn}$ site as steric hindrance further stabilizes $\beta-\mathrm{Zn}_{4} \mathrm{Sb}_{3}$ by restricting long-range $\mathrm{Zn}^{2+}$ migration and extends the operation temperature range of high thermoelectric performance. These results provide insight into the development of mixed-conduction thermoelectric materials, batteries, and other functional materials.

\footnotetext{
${ }^{1}$ State Key Laboratory of Advanced Technology for Materials Synthesis and Processing, Wuhan University of Technology, 430070 Wuhan, China.

${ }^{2}$ Department of Physics and Astronomy, Clemson University, Clemson, SC 29634, USA. ${ }^{3}$ Nanostructure Research Centre, Wuhan University of Technology, 430070 Wuhan, China. ${ }^{4}$ Department of Physics, University of Michigan, Ann Arbor, MI 48109, USA. ${ }^{凶}$ email: jianhe@g.clemson.edu; wujs@whut.edu.cn; tangxf@whut.edu.cn
} 
$\mathrm{M}$ ass transport, along with energy and charge transfer, is ubiquitous in nature and underscores diverse phenomena in science, engineering, and technology. Ionic migration is an important form of mass transport. On the one hand, electric field-driven ionic migration enables a wide range of applications such as batteries, fuel cells, and sensors ${ }^{1}$. On the other hand, ionic migration risks phase instability, for example, precipitation occurs when the mobile ion's electrochemical potential is higher than its atomic counterpart. For the sake of phase stability, the voltage across an ionic conductor needs to be lower than the material-specific temperature-dependent threshold ${ }^{2}$

Here arise two profound questions. First, whether the mass transport in the form of ionic migration can be utilized towards fast materials synthesis. Mass transport mechanisms, different from the traditional thermal diffusion, are a frontier topic of materials science and engineering ${ }^{3}$. Second, whether the interplay between mobile ions, thermal, and electric fields can yield certain microstructures that stabilize the phase at a level beyond the aforementioned "threshold".

$\beta-\mathrm{Zn}_{4} \mathrm{Sb}_{3}$ is a perfect material template to address these questions. $\beta-\mathrm{Zn}_{4} \mathrm{Sb}_{3}$ is known for its complex crystal structure as well as the coexistence of mixed electronic and ionic conduction and promising thermoelectric (TE) performance in the low to intermediate temperature range $(400-700 \mathrm{~K})^{4-13}$.

Unlike most state-of-the-art TE materials that are electronbased semiconductors or semimetals ${ }^{14,15}$, the mobile ions in $\beta$ $\mathrm{Zn}_{4} \mathrm{Sb}_{3}$ play a vital role in its promising TE performance in the context of the Electron-Crystal Phonon-Liquid paradigm ${ }^{16}$. The weakly bonded $\mathrm{Zn}$ interstitials enable highly mobile $\mathrm{Zn}^{2+}$ and also ultra-low thermal conductivity ${ }^{17-20}$. However, broader commercial applications of $\beta-\mathrm{Zn}_{4} \mathrm{Sb}_{3}$ face two long-standing obstacles: developing time- and cost-efficient synthesis recipes and maintaining good phase stability ${ }^{21-28}$ while delivering outstanding TE performance.

To overcome these two $\beta-\mathrm{Zn}_{4} \mathrm{Sb}_{3}$-specific obstacles and to answer the two aforementioned general questions, here we have utilized the fast migration of $\mathrm{Zn}^{2+}$ ions under electrical field and a dynamical growth of three-dimensional (3D) ionic conduction network to attain ultra-fast synthesis of $\beta-\mathrm{Zn}_{4} \mathrm{Sb}_{3}$. The presence of an electric field and the dynamic formation of $3 \mathrm{D}$ ionic conduction network speeded up the mass diffusion process and the chemical reaction of $\mathrm{Zn}$ and $\mathrm{Sb}$ into $\beta-\mathrm{Zn}_{4} \mathrm{Sb}_{3}$ compared to the typical temperature-driven diffusion and chemical reactions. Due to the rapid cooling of the ion channel bulge when the current is cut off, the amorphous nonstoichiometric $\mathrm{Zn}_{4} \mathrm{Sb}_{3}$ layer is formed and encapsulates crystalline $\beta-\mathrm{Zn}_{4} \mathrm{Sb}_{3}$ grain. Such a core-shell crystalline-amorphous micromorphology, especially the amorphous grain boundary, restricts the migration of $\mathrm{Zn}^{2+}$ ions across grains, and thus suppressed $\mathrm{Zn}$ precipitates. Hence, the as-formed core-shell microstructures self-adaptively suppress the thermodynamic re-entry instability of $\beta-\mathrm{Zn}_{4} \mathrm{Sb}_{3}$. Finally, doping by Cd or $\mathrm{Ge}$ on the $\mathrm{Zn}$ site as a steric hindrance further inhibits the migration of $\mathrm{Zn}^{2+}$ ions within each grain. All these mechanisms worked jointly to improve the phase stability of $\beta-\mathrm{Zn}_{4} \mathrm{Sb}_{3}$ and extend the operating temperature range of high TE performance.

\section{Results and discussion}

Fast synthesis. Single-phase pristine $\beta-\mathrm{Zn}_{4} \mathrm{Sb}_{3}$ was formed quickly through an electric field-assisted synthesis (EFAS) process. A schematic diagram of the EFAS apparatus is shown in Fig. 1a. The stoichiometric admixture of $\mathrm{Zn}$ and $\mathrm{Sb}$ powders was loaded into a graphite die, the inner wall of which was coated with a layer of $\mathrm{BN}$ to ensure that maximum current passed through the admixture rather than the die wall. A thermocouple was inserted into the admixture to measure the reaction temperature. The system is evacuated and maintained at a vacuum level $\leq 20 \mathrm{~Pa}$. The $\left(\mathrm{Zn}_{1-x} \mathrm{Cd}_{x}\right)_{4} \mathrm{Sb}_{3}(x=0.005,0.01$, and 0.015$)$ and $\left(\mathrm{Zn}_{1-x} \mathrm{Ge}_{x}\right)_{4} \mathrm{Sb}_{3}(x=0.0025,0.005$, and 0.0075) samples were synthesized under the same EFAS condition as pristine $\beta-\mathrm{Zn}_{4} \mathrm{Sb}_{3}$.

Figure $1 \mathrm{~b}$ displays the key reaction parameters, including the loading pressure, the temperature of the admixture, displacement of the graphite punch, current, voltage, and sintering function (i.e., the derivative of the displacement), as a function of time. The amplitude of current and voltage with a sawtooth waveform and a frequency of $0.4 \mathrm{HZ}$ were applied in the range of $0-9 \mathrm{~A}$ and 1.8-3.6 V, respectively. The highest temperature measured during the passage of the current was $598 \mathrm{~K}$, much lower than the growth-from-the-melt temperature of $1023 \mathrm{~K}^{4,5}$, and the SPS synthesis temperature of $\sim 700 \mathrm{~K}^{29,30}$ for $\beta-\mathrm{Zn}_{4} \mathrm{Sb}_{3}$ based materials. At about $10 \mathrm{~s}$ after the current was on, the sintering function peaked, suggesting the onset of reaction. At $\sim 20 \mathrm{~s}$, the displacement of the graphite punch reached its maximum. After $60 \mathrm{~s}, \mathrm{Zn}_{4} \mathrm{Sb}_{3}, \mathrm{Zn}_{3.96} \mathrm{Cd}_{0.04} \mathrm{Sb}_{3}$, and $\mathrm{Zn}_{3.97} \mathrm{Ge}_{0.03} \mathrm{Sb}_{3}$ compounds were obtained with a relative density higher than $98 \%$, as shown in Fig. 1c and Supplementary Figs. 1 and 2.

A reference pristine sample of $\beta-\mathrm{Zn}_{4} \mathrm{Sb}_{3}$ was prepared using the melt-quench method followed by spark plasma sintering (hereafter named the MQ + SPS sample). The MQ + SPS sample was prepared from high purity elemental $\mathrm{Zn}$ shots $(5 \mathrm{~N})$ and $\mathrm{Sb}$ chunks $(5 \mathrm{~N})$, mixed and sealed in a silica tube under a pressure of $10^{-3} \mathrm{~Pa}$. The tube was slowly heated up to $1023 \mathrm{~K}$ and dwelt for $12 \mathrm{~h}$, followed by quenching in saltwater. The obtained ingot was hand-ground into fine powders and consolidated using an SPS apparatus at $713 \mathrm{~K}$ for $4 \mathrm{~min}$ under a pressure of $30 \mathrm{MPa}$. The relative packing density of the as-prepared pellets, with a diameter of $16 \mathrm{~mm}$ and a thickness of $3 \mathrm{~mm}$, was $97.6 \%$. Supplementary Fig. 3 shows the phase composition of $\mathrm{Zn}_{4} \mathrm{Sb}_{3}$ (MQ + SPS). The X-ray diffraction pattern confirmed the singlephased nature of $\beta-\mathrm{Zn}_{4} \mathrm{Sb}_{3}$ (rhombohedral structure).

Robust properties. $\beta-\mathrm{Zn}_{4} \mathrm{Sb}_{3}$ is a high-performance TE material made of cheap and relatively nontoxic elements. TE materials directly convert heat into electricity through the Seebeck effect, or function as heat pumps via the Peltier effect, thereby playing an important role in our global package of renewable energy options ${ }^{14,15}$. The efficiency of a TE material is gauged by its dimensionless figure of merit $Z T$, defined as $Z T=\alpha^{2} \sigma T /\left(\kappa_{\mathrm{L}}+\kappa_{\mathrm{e}}\right)$, where $\alpha, \sigma, \kappa_{\mathrm{L}}, \kappa_{\mathrm{e}}$, and $T$ are the Seebeck coefficient, electrical conductivity, lattice thermal conductivity, electronic thermal conductivity, and the absolute temperature, respectively ${ }^{14,15}$. The detailed TE transport measurements of the $\mathrm{Zn}_{4} \mathrm{Sb}_{3}$-based samples were performed, as shown in Supplementary Figs. 4-12. The EFAS $\mathrm{Zn}_{4} \mathrm{Sb}_{3}$-based compounds show excellent TE performance. For the EFAS $\mathrm{Zn}_{3.96} \mathrm{Cd}_{0.04} \mathrm{Sb}_{3}$ sample, the maximum $Z T$ value of 1.2 is achieved at $693 \mathrm{~K}$ (cf. Supplementary Fig. 7), while for the EFAS $\mathrm{Zn}_{3.97} \mathrm{Ge}_{0.03} \mathrm{Sb}_{3}$ sample, the maximum $Z T$ value of 1.12 is achieved at $700 \mathrm{~K}$ (cf. Supplementary Fig. 10). Upon doping with $\mathrm{Cd}$ or $\mathrm{Ge}$, the overall $Z T$ value increases in comparison with that of the pristine $\mathrm{Zn}_{4} \mathrm{Sb}_{3}$ sample in the entire range of temperatures (cf. Supplementary Figs. 7 and 10).

In history, the promising TE performance of $\beta-\mathrm{Zn}_{4} \mathrm{Sb}_{3}$-based compounds is overshadowed by the phase instability between 425 and $565 \mathrm{~K}^{18}$, and also the severe ion migration and $\mathrm{Zn}$ precipitates (kinetics instability) under an applied electric field even at room temperature (cf. Supplementary Fig. 13). For example, the MQ+ SPS $\mathrm{Zn}_{4} \mathrm{Sb}_{3}$ sample shows very different TE properties when measured twice, and the sample undergoes irreversible change during the measurement (cf. Supplementary Fig. 14). 

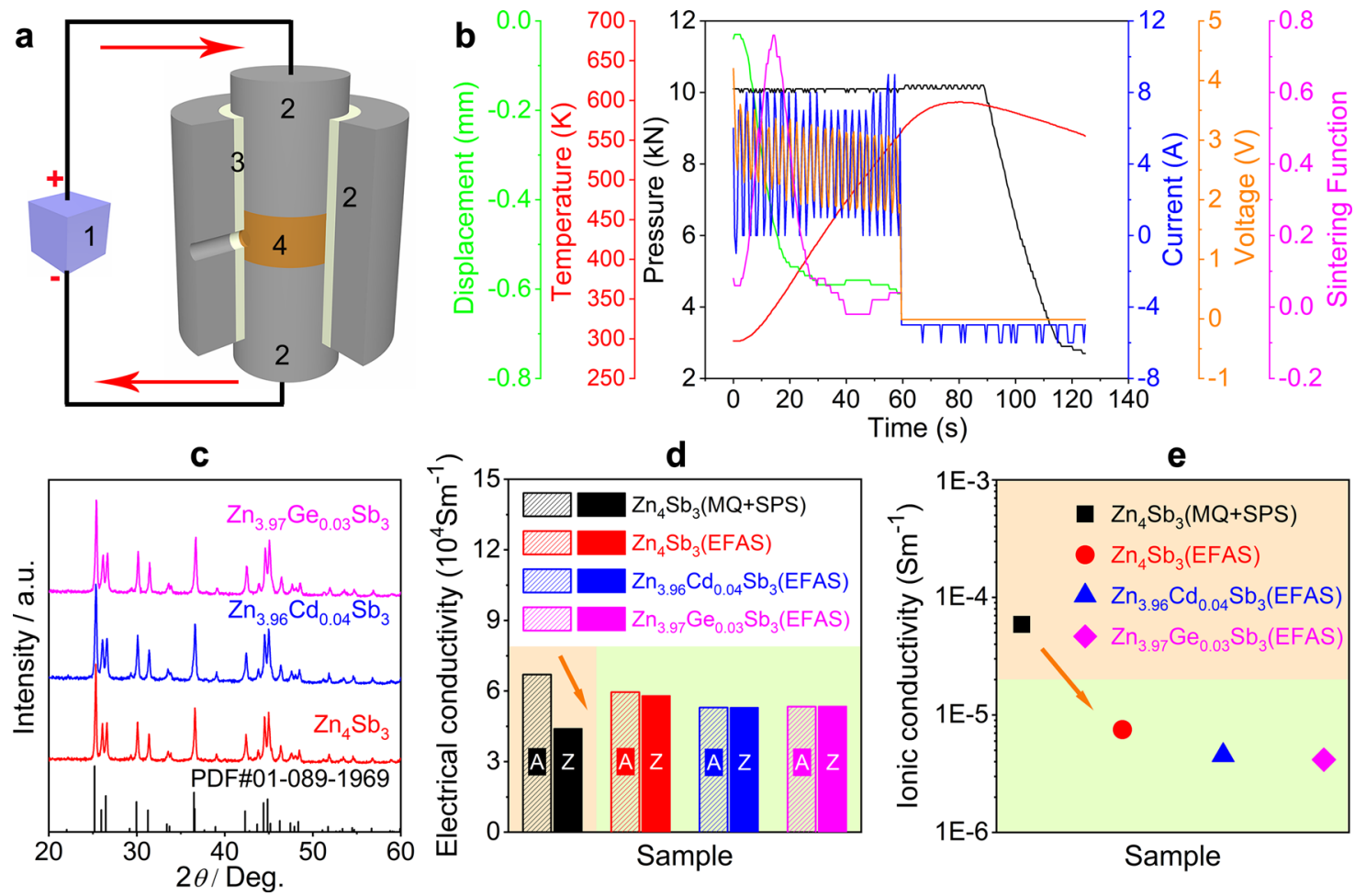

Fig. 1 Ultra-fast synthesis, composition, and properties of $\boldsymbol{\beta}$-Zn4Sb3-based materials. a Schematic diagram of the reaction apparatus, "1-4" represents the DC pulse power supply, graphite die, BN layer, stoichiometric admixture of Zn and Sb powders, respectively. $\mathbf{b}$ Time profile of the reaction parameters, including the loading pressure, temperature of the admixture, displacement of the graphite punch, current, voltage, and sintering function (i.e., the derivative of displacement). c Phase composition of the synthesized samples (standard XRD spectra of PDF\#01-089-1969). $\mathbf{d}$ Room temperature electrical conductivity of $\mathrm{MQ}+\mathrm{SPS} \mathrm{Zn}_{4} \mathrm{Sb}_{3}$, EFAS Zn $\mathrm{n}_{4} \mathrm{Sb}_{3}$, EFAS $\mathrm{Zn}_{3.96} \mathrm{Cd}_{0.04} \mathrm{Sb}_{3}$, and EFAS $\mathrm{Zn}_{3.97} \mathrm{Ge}_{0.03} \mathrm{Sb}_{3}$ samples before and after a test cycle; "A" and " $\mathrm{Z}$ " represent the sample at the beginning and end of the electrical conductivity test. e Room temperature $Z n^{2+}$ ionic conductivities of $M Q+S P S Z n_{4} S b_{3}$, EFAS $\mathrm{Zn}_{4} \mathrm{Sb}_{3}$, EFAS $\mathrm{Zn}_{3.96} \mathrm{Cd}_{0.04} \mathrm{Sb}_{3}$, and EFAS $\mathrm{Zn}_{3.97} \mathrm{Ge}_{0.03} \mathrm{Sb}_{3}$ samples (orange arrow indicating the decline of ionic conductivity).

In contrast, the electrical conductivity, Seebeck coefficient, thermal conductivity, and calculated $Z T$ curves of the EFAS $\mathrm{Zn}_{4} \mathrm{Sb}_{3}$-based compounds are very repeatable and reproducible (cf. Supplementary Figs. 15-20). The room temperature electrical conductivity of all the samples before and after a test cycle is presented in Fig. 1d. It is obvious that the electrical conductivity of the MQ + SPS $\mathrm{Zn}_{4} \mathrm{Sb}_{3}$ sample decreased significantly from $6.7 \times 10^{4}$ to $4.4 \times 10^{4} \mathrm{Sm}^{-1}$, and that of EFAS $\mathrm{Zn}_{4} \mathrm{Sb}_{3}$ sample decreased slightly from $5.9 \times 10^{4}$ to $5.8 \times 10^{4} \mathrm{Sm}^{-1}$, while that of EFAS $\mathrm{Zn}_{3.96} \mathrm{Cd}_{0.04} \mathrm{Sb}_{3}$ sample and that of EFAS $\mathrm{Zn}_{3.97} \mathrm{Ge}_{0.03} \mathrm{Sb}_{3}$ sample remain almost unchanged at about $5.3 \times 10^{4}$ to $5.4 \times 10^{4} \mathrm{Sm}^{-1}$, respectively.

We also measured the $\mathrm{Zn}^{2+}$ conductivity and ran endurance tests under high current density at elevated temperatures. We employed a direct-current (DC) polarization method with electron-blocking electrodes to isolate the ionic conduction by filtering out the electronic conduction ${ }^{2,31,32}$. Commercial zincloaded montmorillonite served as the electrodes. As shown in Supplementary Fig. 21, the $\mathrm{Zn}^{2+}$ migration rate is found to be $3.3 \times 10^{-3} \mathrm{Sm}^{-1}$ at room temperature by the alternating-current (AC) electrochemical impedance spectroscopy (EIS) ${ }^{33-36}$. Solidstate Au|zinc-loaded montmorillonite $\mid \mathrm{Zn}_{4} \mathrm{Sb}_{3}$-based compounds| zinc-loaded montmorillonite|Au pseudo-galvanic cell was constructed (cf. Supplementary Fig. 22), in which all $\mathrm{Zn}_{4} \mathrm{Sb}_{3}$-based samples have a similar size of $8 \times 8 \times 1.3 \mathrm{~mm}^{3}$. When the output voltage is close to $10 \mathrm{~V}$, which is the device limit, the current is

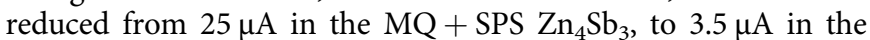
EFAS $\mathrm{Zn}_{4} \mathrm{Sb}_{3}$, to $1.9 \mu \mathrm{A}$ in the EFAS $\mathrm{Zn}_{3.96} \mathrm{Cd}_{0.04} \mathrm{Sb}_{3}$, and finally to $<1.9 \mu \mathrm{A}$ in the EFAS $\mathrm{Zn}_{3.97} \mathrm{Ge}_{0.03} \mathrm{Sb}_{3}$, as shown in Supplementary Figs. 23-26. The room temperature ionic conductivities of
$\mathrm{MQ}+$ SPS $\mathrm{Zn}_{4} \mathrm{Sb}_{3}$, EFAS $\mathrm{Zn}_{4} \mathrm{Sb}_{3}$, EFAS $\mathrm{Zn}_{3.96} \mathrm{Cd}_{0.04} \mathrm{Sb}_{3}$, and EFAS $\mathrm{Zn}_{3.97} \mathrm{Ge}_{0.03} \mathrm{Sb}_{3}$ samples were calculated to be $5.9 \times 10^{-5}$, $7.5 \times 10^{-6}, 4.5 \times 10^{-6}$, and $4.2 \times 10^{-6} \mathrm{Sm}^{-1}$, respectively (cf. Fig. 1e). Hence, the $\mathrm{Zn}^{2+}$ conductivity in the EFAS samples is suppressed by an order of magnitude compared to the MQ + SPS sample, which partially explains the observed improvement in the phase stability and the reproducibility of transport data.

Doping $\mathrm{Cd}$ or Ge further enhanced the phase stability as evidenced by the results of electromigration tests conducted at a temperature of $473 \mathrm{~K}$, a DC current density of $20 \mathrm{~A} / \mathrm{cm}^{2}$, and a charging time of $24 \mathrm{~h}$ (cf. Supplementary Figs. 27 and 28). For comparison, the electromigration test was also carried out on the $\mathrm{MQ}+$ SPS sample under the same conditions. Supplementary Figs. 29-32 show the fracture surface morphology of typical samples after the electromigration tests. Obvious cracking and precipitation of $\mathrm{Zn}$ whiskers are observed on the MQ + SPS $\mathrm{Zn}_{4} \mathrm{Sb}_{3}$ sample (cf. Supplementary Fig. 29). In contrast, the grain surface of the EFAS $\mathrm{Zn}_{4} \mathrm{Sb}_{3}$ sample only becomes rough with no discernible precipitation of $\mathrm{Zn}$ (cf. Supplementary Fig. 30), and the grain surface of the EFAS $\mathrm{Zn}_{3.96} \mathrm{Cd}_{0.04} \mathrm{Sb}_{3}$ sample is very clean with only a small number of microcracks (cf. Supplementary Fig. 31). Even better results are obtained with the EFAS $\mathrm{Zn}_{3.97} \mathrm{Ge}_{0.03} \mathrm{Sb}_{3}$ sample, which shows no cracks but a clean surface (cf. Supplementary Fig. 32).

The above results corroborate that the chemical stability of the EFAS samples is greatly improved. Combined with doping at the Zn sites, particularly doping with Ge, makes the EFAS samples exceptionally stable even under a high DC electric field. In the following sections, we will pinpoint the microscopic origins of the phase formation and the phase stability. 

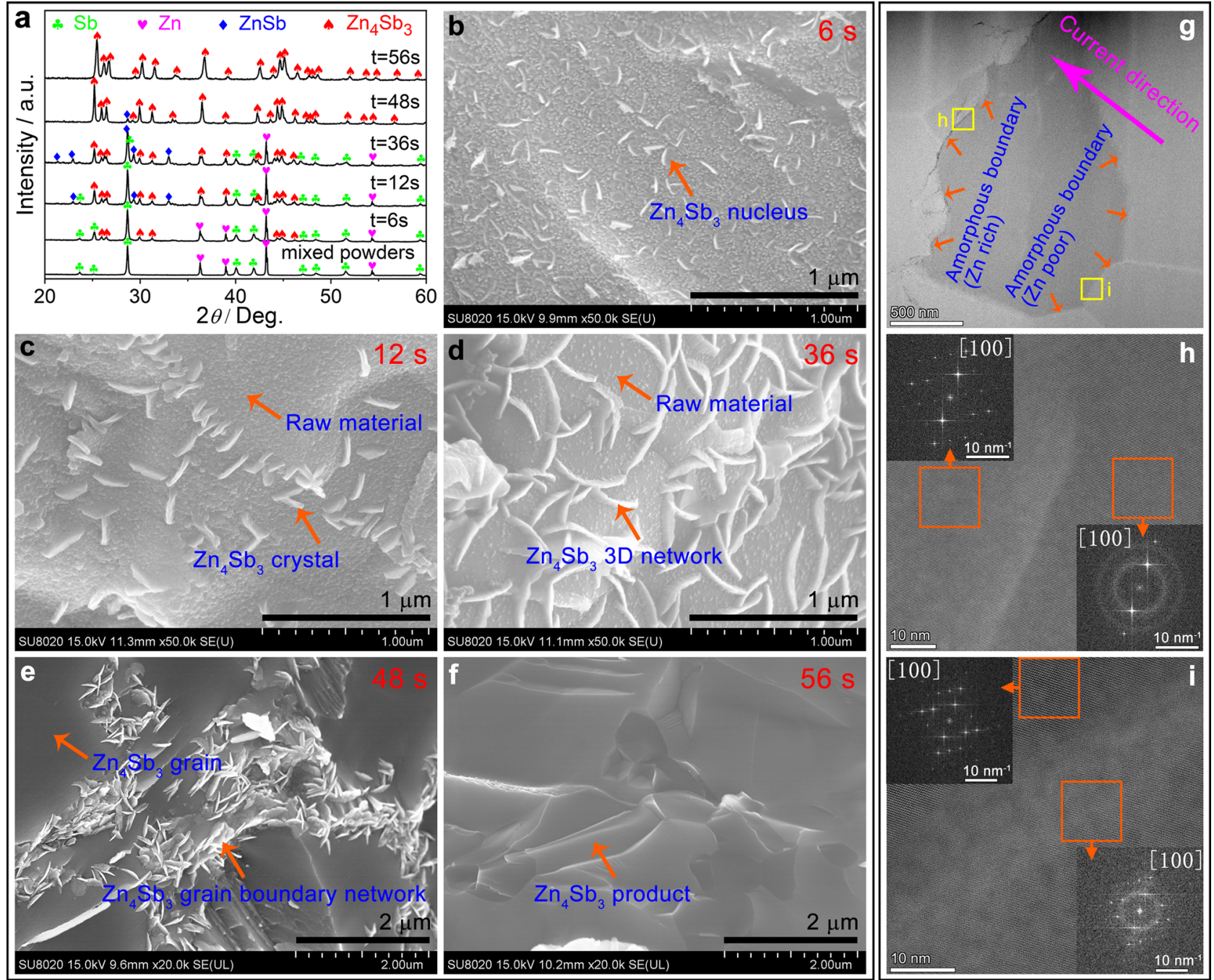

Fig. $\mathbf{2}$ Phase transformation and microstructure evolution during the ultra-rapid synthesis of $\boldsymbol{\beta}-\mathbf{Z} \mathbf{n}_{\mathbf{4}} \mathbf{S} \mathbf{b}_{\mathbf{3}}$ bulk material. a Temporal evolution of the $\beta-\mathrm{Zn}_{4} \mathrm{Sb}_{3}$ phase formation; microstructure transformation process of $\beta$-Zn $\mathrm{n}_{4} \mathrm{Sb}_{3}$ by FESEM: b $6 \mathrm{~s}, \mathbf{c} 12 \mathrm{~s}, \mathbf{d} 36 \mathrm{~s}$, e $48 \mathrm{~s}$, f $56 \mathrm{~s}$. Fine microstructure of $\beta-\mathrm{Zn}_{4} \mathrm{Sb}_{3}$ by TEM: $\mathbf{g}$ macroscopic image of grain, $\mathbf{h}$ macroscopic image of grain boundary located at the downstream side of the current, and the illustration is the diffraction pattern in the orange frame area, $\mathbf{i}$ macroscopic image of grain boundary located at the upstream side of current, and the illustration is the diffraction pattern in the orange frame area.

Phase formation mechanism. To pinpoint the phase formation mechanism of $\beta-\mathrm{Zn}_{4} \mathrm{Sb}_{3}$ in the EFAS process, we first need to differentiate the effect of heating (nondirectional) and the effect of electric field (directional). Specially, we pay close attention to two specific aspects:

Aspect \#1 Temporal window of phase formation.

Single phased $\beta-\mathrm{Zn}_{4} \mathrm{Sb}_{3}$ can be obtained within $60 \mathrm{~s}$ under a pulsed DC field. However, when the charging time extends past $83 \mathrm{~s}$ (cf. Supplementary Fig. 33), it is observed that $\mathrm{ZnSb}$ forms at the upstream side of the sample, and $\mathrm{Zn}$ whiskers precipitate at the sample's downstream side. We invert the die and the sample (turned upside down) and charge for $18 \mathrm{~s}$ (cf. Supplementary Fig. 34), the $\mathrm{Zn}$ and $\mathrm{ZnSb}$ are gone, and a homogeneous $\beta-\mathrm{Zn}_{4} \mathrm{Sb}_{3}$ sample re-emerges. These observations corroborate that (i) the asformed $\beta-\mathrm{Zn}_{4} \mathrm{Sb}_{3}$ serves as a fast transport channel of $\mathrm{Zn}^{2+}$ ions, and (ii) there is a temporal window for the phase formation of $\beta-\mathrm{Zn}_{4} \mathrm{Sb}_{3}$, beyond which the decomposition occurs in the presence of an electric current.

Aspect \#2 The process of phase formation.

The phase formation of $\beta-\mathrm{Zn}_{4} \mathrm{Sb}_{3}$ is the result of the competition between field-assisted phase formation and phase decomposition. Figure 2a depicts a number of intermediate stages in the process of phase formation of $\beta-\mathrm{Zn}_{4} \mathrm{Sb}_{3}$. More detailed experimental results are provided in Supplementary Fig. 41. When $\mathrm{Zn}$ and $\mathrm{Sb}$ powders are in physical contact, a small amount of $\beta-Z_{n} \mathrm{Sb}_{3}$ is formed under the pulsed electric field within less than $10 \mathrm{~s}$, the process is controlled by mutual inter-diffusion of $\mathrm{Zn}$ and $\mathrm{Sb}$. Between 10 and $36 \mathrm{~s}$, both the amount of $\mathrm{ZnSb}$ and $\beta$ $\mathrm{Zn}_{4} \mathrm{Sb}_{3}$ increase simultaneously, as reflected by the peak in the sintering function curve in Fig. 1b. The appearance of $\mathrm{ZnSb}$ suggests that the transport speed of $\mathrm{Zn}^{2+}$ ions is so fast in the ion channels of $\beta-\mathrm{Zn}_{4} \mathrm{Sb}_{3}$ that $\mathrm{Zn}$ cannot be replenished in a timely manner so some are as-formed $\beta-\mathrm{Zn}_{4} \mathrm{Sb}_{3}$ decomposes back into $\mathrm{ZnSb}$ and $\mathrm{Zn}$. Then, the amount of $\mathrm{ZnSb}$ gradually decreases while that of $\beta-\mathrm{Zn}_{4} \mathrm{Sb}_{3}$ further increases, which reflects the fact that the as-formed $\beta-\mathrm{Zn}_{4} \mathrm{Sb}_{3}$ forms a $3 \mathrm{D}$ network and makes more $\mathrm{Zn}$ available to react with $\mathrm{ZnSb}$ into $\beta-\mathrm{Zn}_{4} \mathrm{Sb}_{3}$. Finally, $\beta-\mathrm{Zn}_{4} \mathrm{Sb}_{3}$ is attained at the time of $56 \mathrm{~s}$.

The microstructural evolution confirms that the as-formed $\beta-\mathrm{Zn}_{4} \mathrm{Sb}_{3}$ serves as a fast transport channel of $\mathrm{Zn}^{2+}$ ions, first form nuclei, and crystals, and then form a 3D network, through which $\mathrm{Zn}^{2+}$ can be transported quickly under the electric field (cf. 


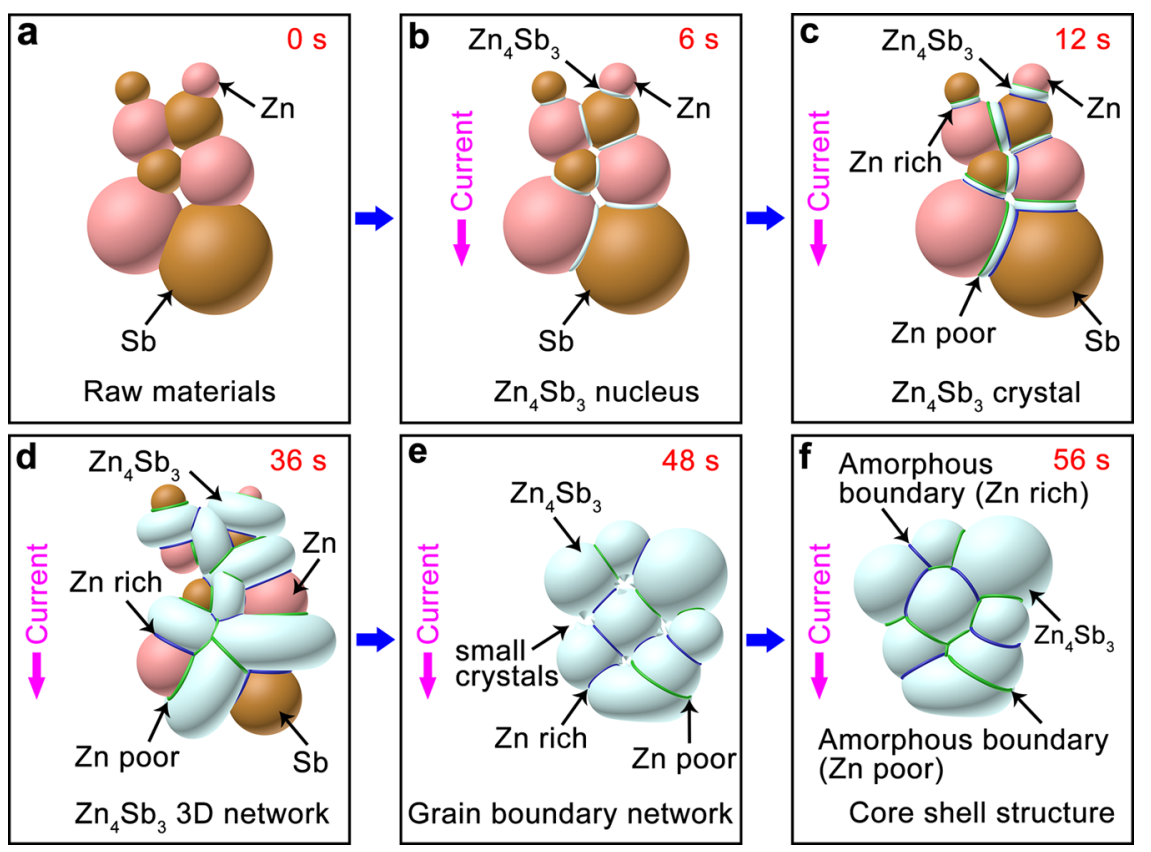

Fig. 3 Schematic diagram of the reaction mechanism. a Raw materials of $\mathrm{Zn}$ and Sb powders with stoichiometric ratio. $\mathbf{b} \beta-\mathrm{Zn}_{4} \mathrm{Sb}_{3}$ nuclei are formed at the contact point between $\mathrm{Zn}$ and $\mathrm{Sb}$ particles when the current is loaded $(6 \mathrm{~s}) . \mathbf{c} \beta-\mathrm{Zn}_{4} \mathrm{Sb}_{3}$ crystal grows up gradually, and the composition in the upstream region of the current is poor in $\mathrm{Zn}$, while the composition in the downstream region is rich in $\mathrm{Zn}(12 \mathrm{~s})$. $\mathbf{d} \beta$ - $\mathrm{Zn} \mathrm{n}_{4} \mathrm{Sb}_{3} 3 \mathrm{D}$ network is formed as growing $\beta-\mathrm{Zn}_{4} \mathrm{Sb}_{3}$ crystals contact each other (36 s). e Special grain boundary network structure filled with a large number of $\beta$ - $\mathrm{Zn}_{4} \mathrm{Sb}_{3}$ nanocrystals is formed due to the ion channel bulge. $\mathbf{f}$ Core-shell microstructure consisted of crystalline $\beta$ - $\mathrm{Zn}_{4} \mathrm{Sb}_{3}$ grains and amorphous off-stoichiometric $\mathrm{Zn}_{4} \mathrm{Sb}_{3}$ grain boundaries that are formed when the current is off.

Figure $2 \mathrm{~b}-\mathrm{f}$ ). Finer microstructure details of $\beta-\mathrm{Zn}_{4} \mathrm{Sb}_{3}$ were investigated by TEM (cf. Figure $2 \mathrm{~g}-\mathrm{i}$ ). The crystal grain shows a perfect $\beta-\mathrm{Zn}_{4} \mathrm{Sb}_{3}$ lattice, while the grain boundary appears to be amorphous. The amorphous grain boundary located at the downstream side of current is rich in $\mathrm{Zn}$ (cf. Fig. 2h), while the counterpart at the upstream side of current is poor in $\mathrm{Zn}$ (cf. Fig.e 2i), de facto forming a special core-shell structure composite.

These results point toward a schematic diagram of the reaction mechanism as shown in Fig. 3a-f. When $\mathrm{Zn}$ is in physical contact with $\mathrm{Sb}$, under the pulse current, $\beta-\mathrm{Zn}_{4} \mathrm{Sb}_{3}$ nucleus forms (cf. Fig. $3 b$ ). Due to the high ionic conductivity of $\mathrm{Zn}^{2+}$ in $\beta-\mathrm{Zn}_{4} \mathrm{Sb}_{3}$, $\mathrm{Zn}^{2+}$ ions are easily transported through the as-formed $\beta-\mathrm{Zn}_{4} \mathrm{Sb}_{3}$ and react with $\mathrm{Sb}$ forming additional $\beta-\mathrm{Zn}_{4} \mathrm{Sb}_{3}$ in spite of $\mathrm{Zn}$ being separated from $\mathrm{Sb}$ by $\beta-\mathrm{Zn}_{4} \mathrm{Sb}_{3}$ (cf. Fig. $3 \mathrm{c}$ ). Due to the transport speed of $\mathrm{Zn}^{2+}$ in the ion channel of $\beta-\mathrm{Zn}_{4} \mathrm{Sb}_{3}$ mismatches the local supply of fresh $\mathrm{Zn}$, the upstream and downstream side of grain boundaries tend to be, respectively, poor and rich in $\mathrm{Zn}$ along the current direction. As $\beta-\mathrm{Zn}_{4} \mathrm{Sb}_{3}$ crystals contact each other (at $\sim 36 \mathrm{~s}$ ), a 3D network is formed (cf. Figure $3 \mathrm{~d}$ ), which greatly promotes the transport speed and scope of $\mathrm{Zn}^{2+}$ ions and makes $\beta-\mathrm{Zn}_{4} \mathrm{Sb}_{3}$ grains grow rapidly. In particular, a large number of $\beta-\mathrm{Zn}_{4} \mathrm{Sb}_{3}$ nanocrystals are formed at the ion channel bulges, these nanocrystals fill the voids between $\mathrm{Zn}_{4} \mathrm{Sb}_{3}$ grains, and lead to the densification of material (cf. Fig. 3e). Normally, the current discharge at the grain boundary produces highly intensive Joule heating. When the current is off, the rapid cooling at the contact quenches nanocrystals to amorphous, forming the core-shell crystalline-amorphous microstructure (cf. Fig. 3f).

Phase stability mechanism. The core-shell crystalline-amorphous micromorphology somewhat explains the observed improvement of chemical stability of the EFAS samples because the amorphous layer is not ionic conducting. More details are provided by the in situ transmission electron microscopy study. The responses to an electric field applied to $\mathrm{MQ}+\mathrm{SPS} \mathrm{Zn}_{4} \mathrm{Sb}_{3}$ sample and EFAS $\mathrm{Zn}_{4} \mathrm{Sb}_{3}$ sample are recorded in detail in the Supporting information (cf. Supplementary Movies 1 and 2).

In addition, Fig. $4 \mathrm{a}-\mathrm{f}$ shows different stages (in time) when the current flows through the EFAS $\mathrm{Zn}_{4} \mathrm{Sb}_{3}$ sample. When the applied voltage exceeds $0.69 \mathrm{~V}$, the grain boundary is gradually widened, increasing from $\sim 20$ to $\sim 74 \mathrm{~nm}$, and, finally, the grain collapses and the material becomes unstable. Figure $4 \mathrm{~g}-\mathrm{i}$ shows the high-angle annular dark-field (HAADF) image and its corresponding energy-dispersive X-ray spectroscopy (EDS) spectrum of the EFAS $\mathrm{Zn}_{4} \mathrm{Sb}_{3}$ sample after the current is turned off. It is obvious that the $\mathrm{Zn}^{2+}$ ions migrate downstream along the current, and the upstream grains crack and fragment due to the loss of $\mathrm{Zn}$. Fine structures of the grain boundary were studied (cf. Fig. 4j-1). White particles, aka $\mathrm{Zn}$ metal, are precipitated at the junction of the two grains (cf. Fig. 4l) and are amorphous (cf. Fig. 4k). Interestingly, the surrounding areas of the white precipitates become crystalline. Apparently, when the applied voltage on the material is higher than the critical voltage, the amorphous grain boundary crystallizes into $\beta-\mathrm{Zn}_{4} \mathrm{Sb}_{3}$, which conducts $\mathrm{Zn}^{2+}$ ions under the electric field and finally destabilizes the grain. On the contrary, as long as a voltage is applied, the grains of $\mathrm{MQ}+\mathrm{SPS} \mathrm{Zn}_{4} \mathrm{Sb}_{3}$ sample will crack and disintegrate continually, and there is no phenomenon of grain boundary widening (cf. Supplementary Fig. 45 and Supplementary Movie 2).

Figure 5 shows the schematic diagram of $\beta-\mathrm{Zn}_{4} \mathrm{Sb}_{3}$ microstructure derived by different synthesis methods. For MQ + SPS $\mathrm{Zn}_{4} \mathrm{Sb}_{3}$ sample, ion channels run through the grains to the entire bulk as there is no ion migration blocking mechanism (cf. Fig. 5a). While for the EFAS $\mathrm{Zn}_{4} \mathrm{Sb}_{3}$ sample, ion channels are limited to the interior of the grain, and the amorphous layer on 

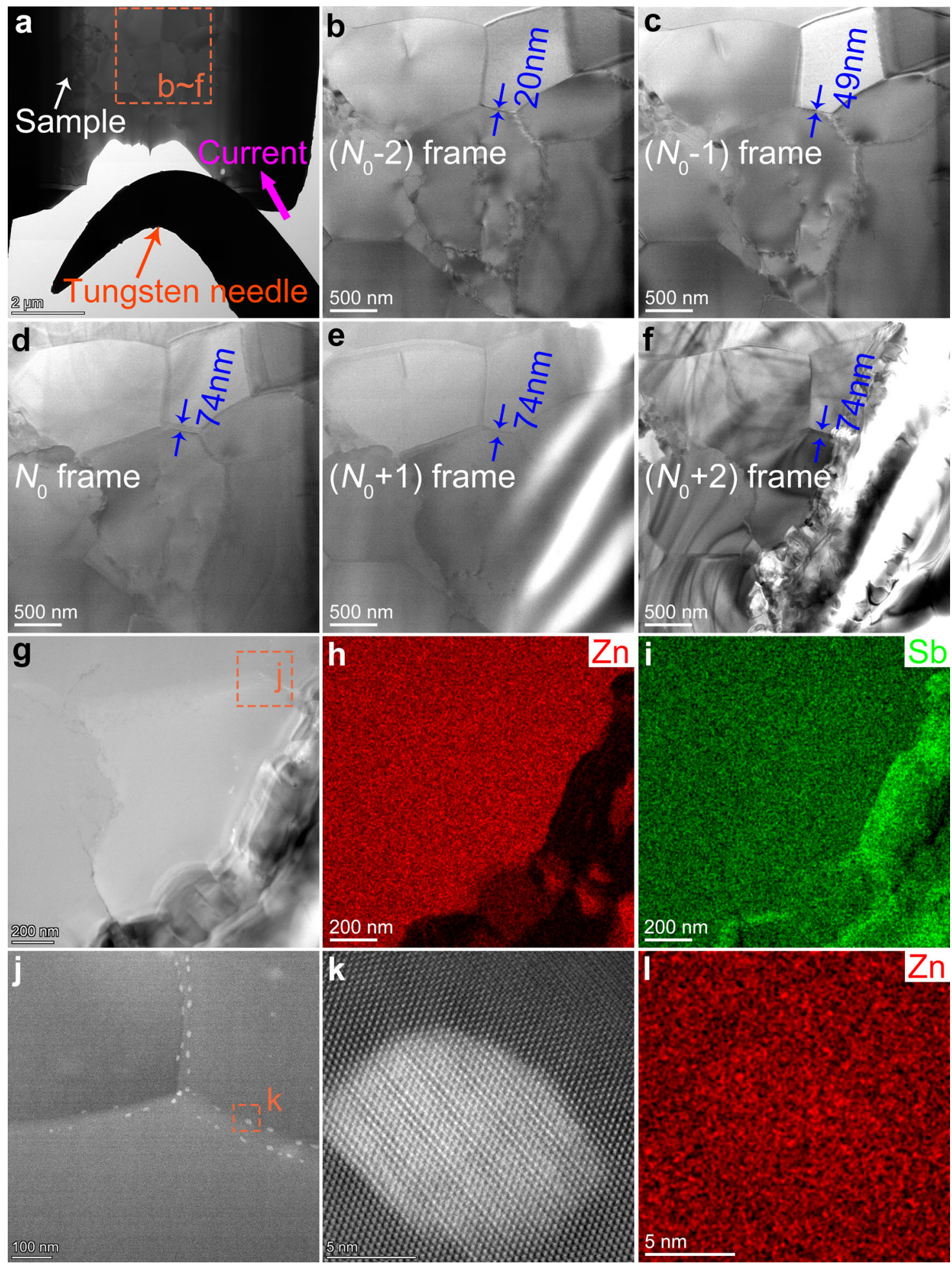

Fig. 4 In situ microstructure evolution. a-f Different stages (in time) during the current flow through the EFAS $\mathrm{Zn}_{4} \mathrm{Sb}_{3}$ sample (the grain boundary reaches the widest at the $N_{0}$ frame). $\mathbf{g}$ - $\mathbf{i}$ The HAADF image and the corresponding EDS spectrum of EFAS $\mathrm{Zn}_{4} \mathrm{Sb}_{3}$ sample after the current are turned off. $\mathbf{j}$ Enlarged HAADF image of the grain boundary area delineated by an orange border in ( $\mathbf{g}$ ); white particles are precipitated at the junction of the two grains. $\mathbf{k}-\mathbf{I}$ Highresolution images and EDS spectra of white particles.

the grain boundary (respectively, poor and rich in $\mathrm{Zn}$ ) blocks the formation of the network due to the lack of ion channels, so as to improve the stability of the bulk material (cf. Fig. 5b). Moreover, the literatures $5,37,38$ show that foreign elements can replace dynamic $\mathrm{Zn}$, and thus reduce the ionic conduction and thus improve the stability. To sum up, the core-shell crystalline- amorphous microstructure combined with doping by foreign elements (i.e., $\mathrm{Cd}$ or $\mathrm{Ge}$ ) at the $\mathrm{Zn}$ sites inhibit the migration of dynamic $\mathrm{Zn}^{2+}$ ions at multiple scales, and improve the thermodynamic (phase transition, cf. Supplementary Figs. 43 and 44) and kinetic (ionic migration, cf. Supplementary Figs. 29-32) stability of $\beta-\mathrm{Zn}_{4} \mathrm{Sb}_{3}$. 

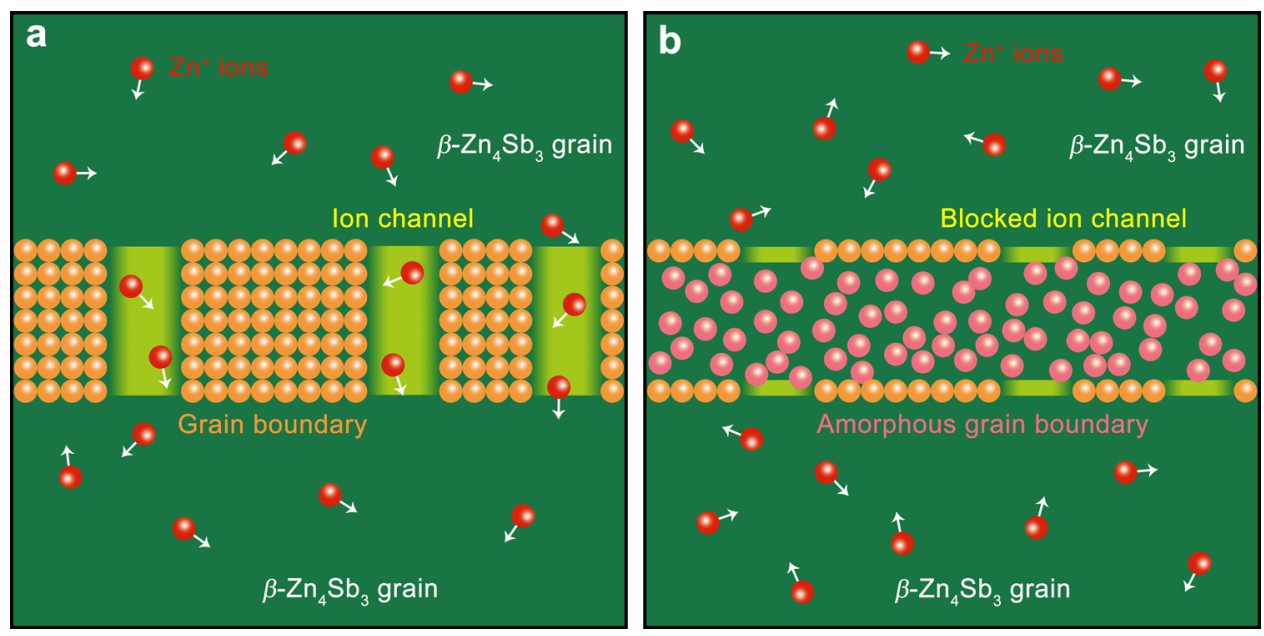

Fig. 5 Ion blocking mechanism. a lon channels run through the grains to form a network all over the MQ $+\mathrm{SPS}_{\mathrm{Zn}} \mathrm{Sb}_{3}$ bulk material. b lon channels in EFAS $\mathrm{Zn}_{4} \mathrm{Sb}_{3}$ bulk material are limited to the interior of the grain, and the amorphous layer on the grain boundary (including rich $\mathrm{Zn}$ and poor $\mathrm{Zn}$ ) blocks the formation of the network due to the lack of ion channel.

In summary, we have prepared a series of $\beta-\mathrm{Zn}_{4} \mathrm{Sb}_{3}$-based compounds with different dopants by an EFAS technique. The mechanism of phase formation and decomposition, and chemical stability, along with the TE transport properties, have been discussed in detail. Under the DC electric field, the ion transport channel in $\beta-\mathrm{Zn}_{4} \mathrm{Sb}_{3}$ enables fast mass transport and participates in chemical reactions. A dense EFAS $\beta-Z_{4} \mathrm{Sb}_{3}$-based bulk material can be formed within $60 \mathrm{~s}$. The resulting bulk composite material has a crystal-amorphous core-shell micromorphology. The as-formed composite microstructure, in conjunction with $\mathrm{Cd} / \mathrm{Ge}$ doping, stabilizes the high TE performance of $\beta-\mathrm{Zn}_{4} \mathrm{Sb}_{3}$ via suppressing the long-range $\mathrm{Zn}$ ions migration and precipitates of $\mathrm{Zn}$ on the grain boundaries. Specifically, the $\mathrm{Zn}^{2+}$ ionic conductivity is decreased by more than an order magnitude from $5.9 \times 10^{-5} \mathrm{Sm}^{-1}$ for the MQ + SPS sample to $4.2 \times 10^{-6} \mathrm{Sm}^{-1}$ for the Ge-doped structure. Moreover, $\beta-\mathrm{Zn}_{4} \mathrm{Sb}$ was doped with 0.75 at.\% Ge shows essentially no change when carrying the current density of $20 \mathrm{~A} / \mathrm{cm}^{2}$ at $473 \mathrm{~K}$ for $24 \mathrm{~h}$. The Cd-doped structure $\mathrm{Zn}_{3.96} \mathrm{Cd}_{0.04} \mathrm{Sb}_{3}$ attained $Z T_{\max }=1.2$, at $693 \mathrm{~K}$, while the Ge-doped $\mathrm{Zn}_{3.97} \mathrm{Ge}_{0.03} \mathrm{Sb}_{3}$ sample reached $Z T_{\max }=1.12$, at $700 \mathrm{~K}$. The synthesis method can be in principle extended to, for example, $\mathrm{ZnSb}, \mathrm{Cu}_{2} \mathrm{Se}$, and $\mathrm{Cu}_{2} \mathrm{~S}$ (cf. Supplementary Figs. 46-48), which is of great technical implications.

\footnotetext{
Methods

Synthesis. Four grams of $\mathrm{Zn}(5 \mathrm{~N}, 200$ mesh) and $\mathrm{Sb}(5 \mathrm{~N}, 200$ mesh) or $\mathrm{Cd}(5 \mathrm{~N}$, 200 mesh) and Ge (5N, 200 mesh) powders were weighed according to the stoichiometric ratio and were thoroughly mixed in an agate mortar for $20 \mathrm{~min}$. The mixed raw powders were transferred into the mold $(\Phi 16 \mathrm{~mm})$ in Fig. 1a. The inner wall of the graphite mold was coated by a layer of $\mathrm{BN}$ to ensure most current flows through the powder admixture. A thermocouple was inserted into the admixture to measure the reaction temperature. In a typical process, a vacuum level $\leq 20 \mathrm{~Pa}$ was maintained. Next, a pulsed sawtooth-shaped current is applied to the mold for $60 \mathrm{~s}$. The resulting pellet with a diameter of $16 \mathrm{~mm}$ and a height of $3 \mathrm{~mm}$ had a relative density of more than $98 \%$. The ingot was cut into appropriate shapes for the TE property measurements and electromigration tests.

Moreover, the EFAS processes for $\mathrm{Bi}_{2} \mathrm{Te}_{3}, \mathrm{ZnSb}, \mathrm{Cu}_{2} \mathrm{Se}$, and $\mathrm{Cu}_{2} \mathrm{~S}$ compounds are really similar.
}

Test of ionic conductivity of $\mathbf{Z n}^{2+}$. The migration rate of $\mathrm{Zn}^{2+}$ ions in the commercial zinc-loaded montmorillonite was tested through AC EIS. A solid-state $\mathrm{Au} \mid z i n c-l o a d e d$ montmorillonite| $\mathrm{Zn}_{4} \mathrm{Sb}_{3}$-based compounds|zinc-loaded montmorillonite $\mid A u$ pseudo-galvanic cell was constructed, in which all $\mathrm{Zn}_{4} \mathrm{Sb}_{3}$-based samples have a similar size of $8 \times 8 \times 1.3 \mathrm{~mm}^{3}$. Then, based on the DC polarization measurements, the resulting ionic conductivities of $\mathrm{Zn}_{4} \mathrm{Sb}_{3}$ (MQ $+\mathrm{SPS}$ ), $\mathrm{Zn}_{4} \mathrm{Sb}_{3}$ (EFAS), $\mathrm{Zn}_{3.96} \mathrm{Cd}_{0.04} \mathrm{Sb}_{3}$ (EFAS), and $\mathrm{Zn}_{3.97} \mathrm{Ge}_{0.03} \mathrm{Sb}_{3}$ (EFAS) at room temperature could be obtained.
Chemical electromigration tests. Electromigration tests were conducted at a temperature of $473 \mathrm{~K}$, with the DC current density of $20 \mathrm{~A} / \mathrm{cm}^{2}$, and the charging time of $24 \mathrm{~h}$. High-purity argon gas of $100 \mathrm{~Pa}$ filled the cavity to avoid a short circuit.

Characterization. The phase purity of all samples was inspected by X-ray powder diffraction (Empyrean, $\mathrm{Cu} \mathrm{K}$ line, PANalytical, Holland). Images of freshly fractured surfaces were taken by field emission scanning electron microscopy (SU8000, Hitachi, Japan) with EDS (XFlash6160, Bruker, Germany). Back-scattered images were taken by EPMA (JXA-8100, JEOL, Japan). A direct characterization of the samples' atomic structures and structural evolution during the process of electrification was carried out on transmission electron microscopy (Talos F200s, FEI) and double spherical aberration-corrected transmission electron microscopy (Titan Themis G2 60-300, FEI). The samples for TEM observation were prepared by ion milling with liquid nitrogen (PIPS 695, Gatan) and focused ion beam milling (Helios Nanolab G3 UC, FEI). In situ biasing experiments were performed within the TEM column using a TEM-STM holder (Pico Femto, Zeptools). The low- and high-temperature heat flow of the $\mathrm{Zn}_{4} \mathrm{Sb}_{3}$-based samples, respectively, was detected by Q2000 (TA, USA).

The electrical conductivity $(\sigma)$ and the Seebeck coefficient $(\alpha)$ were measured simultaneously using a commercial equipment (ZEM-3, Ulvac, Japan). The hightemperature Hall coefficient $\left(R_{\mathrm{H}}\right)$ was measured in a magnetic performance testing system (NYMS, China), using the van der Pauw method under a reversible magnetic field of $1.5 \mathrm{~T}$. The low-temperature $\sigma$ and $R_{\mathrm{H}}$ between 10 and $300 \mathrm{~K}$ were measured on a Physical Properties Measurement System (PPMS-9, Quantum Design, USA). The effective carrier concentration $\left(n_{\mathrm{H}}\right)$ was calculated by the formula: $n_{\mathrm{H}}=1 / e R_{\mathrm{H}}$, where $e$ is the electron charge. The Hall mobility follows from $\mu_{\mathrm{H}}=\sigma R_{\mathrm{H}}$. The thermal conductivity was calculated from the relation $\kappa=D \times c_{\mathrm{p}} \times \rho$, where $D$ is the thermal diffusivity coefficient, $c_{\mathrm{p}}$ is the specific heat capacity, and $\rho$ is the bulk density. $D$ was measured using an LFA457 (Netzsch, Germany) laser flash apparatus. $c_{\mathrm{p}}$ was taken as the Dulong-Petit law value. $\rho$ was obtained by the Archimedes method.

\section{Data availability}

The authors declare that all data supporting the findings of this work are available from the corresponding authors upon reasonable request.

Received: 11 February 2021; Accepted: 17 September 2021; Published online: 19 October 2021

\section{References}

1. Lidiard, A. B. Ionic Conductivity (Springer, 1957).

2. Qiu, P. F. et al. Suppression of atom motion and metal deposition in mixed ionic electronic conductors. Nat. Commun. 9, 2910-2917 (2018).

3. Incropera, F. P., Lavine, A. S., Bergman, T. L., \& DeWitt, D. P. Fundamentals of Heat and Mass Transfer (Wiley, 2007).

4. Wang, S. Y., Li, H., Qi, D. K., Xie, W. J. \& Tang, X. F. Enhancement of the thermoelectric performance of $\beta-\mathrm{Zn}_{4} \mathrm{Sb}_{3}$ by in situ nanostructures and minute Cd-doping. Acta Mater. 59, 4805-4817 (2011). 
5. Wang, S. Y. et al. The realization of a high thermoelectric Fig. of merit in Gesubstituted $\beta-\mathrm{Zn}_{4} \mathrm{Sb}_{3}$ through band structure modification. J. Mater. Chem. 22, 13977-13985 (2012).

6. Lin, J. P. et al. Unexpected high-temperature stability of $\beta-\mathrm{Zn}_{4} \mathrm{Sb}_{3}$ opens the door to enhanced thermoelectric performance. J. Am. Chem. Soc. 136, 1497-1504 (2014).

7. Snyder, G. J., Christensen, M., Nishibori, E., Caillat, T. \& Iversen, B. B. Disordered zinc in $\mathrm{Zn}_{4} \mathrm{Sb}_{3}$ with phonon-glass and electron-crystal thermoelectric properties. Nat. Mater. 3, 458-463 (2004).

8. Pedersen, B. L., Yin, H., Birkedal, H., Nygren, M. \& Iversen, B. B. Cd substitution in $\mathrm{M}_{\mathrm{x}} \mathrm{Zn}_{4-\mathrm{x}} \mathrm{Sb}_{3}$ : effect on thermal stability, crystal structure, phase transitions, and thermoelectric performance. Chem. Mater. 22, 2375-2383 (2010).

9. Wei, P. C. et al. Enhancement of thermoelectric Fig. of merit in $\beta-\mathrm{Zn}_{4} \mathrm{Sb}_{3}$ by indium doping control. Appl. Phys. Lett. 107, 123902-123906 (2015).

10. Ren, B. J. et al. Enhancement of thermoelectric performance of $\beta-\mathrm{Zn}_{4} \mathrm{Sb}_{3}$ through resonant distortion of electronic density of states doped with $\mathrm{Gd}$. J. Mater. Chem. A 3, 11768-11772 (2015).

11. Mozharivskyj, Y. et al. $\mathrm{Zn}_{13} \mathrm{Sb}_{10}$ : a structural and landau theoretical analysis of its phase transitions. Chem. Mater. 18, 822-831 (2006).

12. Mozharivskyj, Y., Pecharsky, A. O., Bud'ko, S. \& Miller, G. J. A promising thermoelectric material: $\mathrm{Zn}_{4} \mathrm{Sb}_{3}$ or $\mathrm{Zn}_{6-\delta} \mathrm{Sb}_{5}$. its composition, structure, stability, and polymorphs. structure and stability of $\mathrm{Zn}_{1-\delta} \mathrm{Sb}$. Chem. Mater. 16, $1580-1589$ (2004).

13. Lo, C.-W. T., Svitlyk, V., Chernyshov, D. \& Mozharivskyj, Y. The updated Zn$\mathrm{Sb}$ phase diagram. how to make pure $\mathrm{Zn}_{13} \mathrm{Sb}_{10}\left({ }^{\prime} \mathrm{Zn}_{4} \mathrm{Sb}_{3}\right.$ "). Dalton Trans. 47, 11512-11520 (2018).

14. Rowe, D. M. CRC Handbook of Thermoelectrics (CRC Press, 1995).

15. Goldsmid, H. J. Introduction to Thermoelectricity (Springer, 2010).

16. Liu, H. L. et al. Copper ion liquid-like thermoelectrics. Nat. Mater. 11, 422-425 (2012).

17. Bjerg, L., Iversen, B. B. \& Madsen, G. K. H. Modeling the thermal conductivities of the zinc antimonides $\mathrm{ZnSb}$ and $\mathrm{Zn}_{4} \mathrm{Sb}_{3}$. Phys. Rev. B 89 , 024304-024311 (2014).

18. Cargnoni, F. et al. Interstitial $\mathrm{Zn}$ atoms do the trick in thermoelectric zinc antimonide, $\mathrm{Zn}_{4} \mathrm{Sb}_{3}$ : a combined maximum entropy method X-ray electron density and ab initio electronic structure study. Chem. Eur. J. 10, 3861-3870 (2004).

19. Li, X. D., Carrete, J., Lin, J. P., Qiao, G. J. \& Wang, Z. Atomistic origin of glasslike $\mathrm{Zn}_{4} \mathrm{Sb}_{3}$ thermal conductivity. Appl. Phys. Lett. 103, 103902-103905 (2013).

20. Fischer, A. et al. Thermal and vibrational properties of thermoelectric ZnSb: exploring the origin of low thermal conductivity. Phys. Rev. B 91, 224309-224321 (2015).

21. Yang, J. et al. Effect of $\mathrm{Zn}$ migration on the thermoelectric properties of $\mathrm{Zn}_{4} \mathrm{Sb}_{3}$ material. Ceram. Int. 43, 15275-15280 (2017).

22. Kunioka, H., Yamamoto, A., Iida, T. \& Obara, H. Electrical current dependence of the ionic conduction in $\mathrm{Zn}_{4} \mathrm{Sb}_{3}$. Appl. Phys. Express 10, 095801-095804 (2017).

23. Yin, H., Christensen, M., Lock, N. \& Iversen, B. B. Zn migration during spark plasma sintering of thermoelectric $\mathrm{Zn}_{4} \mathrm{Sb}_{3}$. Appl. Phys. Lett. 101, 043901-043903 (2012)

24. Yin, H., Pedersen, B. L. \& Iversen, B. B. Thermal stability of high performance thermoelectric $\beta-\mathrm{Zn}_{4} \mathrm{Sb}_{3}$ in argon. Eur. J. Inorg. Chem. 2011, 2733-2737 (2011).

25. Caillat, T., Fleurial, J. P. \& Borshchevsky, A. Preparation and thermoelectric properties of semiconducting $\mathrm{Zn}_{4} \mathrm{Sb}_{3}$. J. Phys. Chem. Solids 58, 1119-1125 (1997).

26. Hung, L. T. et al. In operando study of high-performance thermoelectric materials for power generation: a case study of $\beta-\mathrm{Zn}_{4} \mathrm{Sb}_{3}$. Adv. Electron. Mater. 3, 1700223-1700230 (2017).

27. Jakob, M., Grauer, M., Ziolkowski, P. \& Oeckler, O. Decomposition phenomena of $\mathrm{Zn}_{13-\delta} \mathrm{Sb}_{10}$ under working conditions of thermoelectric generators and minimum current densities for electromigration. ACS Appl. Energy Mater. 3, 2103-2109 (2020).

28. Rabøl Jørgensen, L. et al. Operando X-ray scattering study of thermoelectric $\beta$ $\mathrm{Zn}_{4} \mathrm{Sb}_{3}$. IUCrJ 7, 100-104 (2020).

29. Yin, H., Blichfeld, A. B., Christensen, M. \& Iversen, B. B. Fast direct synthesis and compaction of homogenous phase-pure thermoelectric $\mathrm{Zn}_{4} \mathrm{Sb}_{3}$. ACS Appl. Mater. Interfaces 6, 10542-10548 (2014).

30. Lin, J. P. et al. Thermoelectric properties of $\mathrm{Zn}_{4} \mathrm{Sb}_{3}$ composites with incomplete reaction. J. Electron. Mater. 48, 1159-1163 (2018).

31. Yokota, I. On the electrical conductivity of cuprous sulfide: a diffusion theory. J. Phys. Soc. Jpn. 8, 595-602 (1953).

32. Yokota, I. On the theory of mixed conduction with special reference to conduction in silver sulfide group semiconductors. J. Phys. Soc. Jpn. 16, 2213-2223 (1961).
33. Kamaya, N. et al. A lithium superionic conductor. Nat. Mater. 10, 682-686 (2011).

34. Murugan, R., Thangadurai, V. \& Weppner, W. Fast lithium ion conduction in garnet-type $\mathrm{Li}_{7} \mathrm{La}_{3} \mathrm{Zr}_{2} \mathrm{O}_{12}$. Angew. Chem. Int. Ed. 46, 7778-7781 (2007).

35. Seino, Y., Ota, T., Takada, K., Hayashi, A. \& Tatsumisago, M. A sulphide lithium super ion conductor is superior to liquid ion conductors for use in rechargeable batteries. Energ. Environ. Sci. 7, 627-631 (2014).

36. Zhang, Z. et al. $\mathrm{Na}_{11} \mathrm{Sn}_{2} \mathrm{PS}_{12}$ : a new solid state sodium superionic conductor. Energ. Environ. Sci. 11, 87-93 (2018)

37. Chen, W. B. \& Li, J. B. Origin of the low thermal conductivity of the thermoelectric material $\beta-\mathrm{Zn}_{4} \mathrm{Sb}_{3}$ : an ab initio theoretical study. Appl. Phys. Lett. 98, 241901-241903 (2011).

38. Liu, M., Qin, X., Liu, C., Pan, L. \& Xin, H. Ag and Cu doping and their effects on the thermoelectric properties of $\beta-\mathrm{Zn}_{4} \mathrm{Sb}_{3}$. Phys. Rev. B 81, 245215-245224 (2010).

\section{Acknowledgements}

We acknowledge support from the National Key Research and Development Program of China (2019YFA0704900), the Natural Science Foundation of China (Grant Nos. 51632006, 51521001, and 52072282), and the 111 Project of China (Grant No. B07040). D.Y. acknowledges support from the Fundamental Research Funds for the Central Universities (WUT: 2020IVA097) and the Hubei Post-doctoral Innovation Research Post Fund (second batch). J.H. acknowledges support from the NSF DMR 1307740. The S/ TEM work was performed at the Nanostructure Research Center (NRC), which is supported by the Fundamental Research Funds for the Central Universities (WUT: 2021III016GX). Besides, D.Y. is grateful to Meijun Yang and Xiaolei Nie for their help with EPMA in Materials Research and Test Center of WHUT, and to Prof. Wenyu Zhao and Shifang Ma for their help with high-temperature Hall coefficient measurements in State Key Laboratory of Advanced Technology for Materials Synthesis and Processing.

\section{Author contributions}

D.Y. and X.T conceived this work. D.Y., X.S., Y.Yan and Y.L. prepared the materials and tested their TE performance; D.Y. and J.L. tested the ionic conductivity of $\mathrm{Zn}^{2+}$; D.Y. did the chemical electromigration tests; H.B., T.L., H.L., Y.Yu and J.W. carried out the TEM experiment and analyzed the data; D.Y., J.H., Q.Z. and C.U. analyzed the experimental data; D.Y., J.H. and X.T. cowrote the manuscript. All authors reviewed, discussed, and approved the results and conclusions.

\section{Competing interests}

The authors declare no competing interests.

\section{Additional information}

Supplementary information The online version contains supplementary material available at https://doi.org/10.1038/s41467-021-26265-0.

Correspondence and requests for materials should be addressed to Jian $\mathrm{He}$, Jinsong $\mathrm{Wu}$ or Xinfeng Tang.

Peer review information Nature Communications thanks the anonymous reviewers for their contribution to the peer review of this work.

Reprints and permission information is available at http://www.nature.com/reprints

Publisher's note Springer Nature remains neutral with regard to jurisdictional claims in published maps and institutional affiliations.

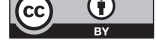

Open Access This article is licensed under a Creative Commons Attribution 4.0 International License, which permits use, sharing, adaptation, distribution and reproduction in any medium or format, as long as you give appropriate credit to the original author(s) and the source, provide a link to the Creative Commons license, and indicate if changes were made. The images or other third party material in this article are included in the article's Creative Commons license, unless indicated otherwise in a credit line to the material. If material is not included in the article's Creative Commons license and your intended use is not permitted by statutory regulation or exceeds the permitted use, you will need to obtain permission directly from the copyright holder. To view a copy of this license, visit http://creativecommons.org/ licenses/by/4.0/.

(C) The Author(s) 2021 